\title{
Medication-related knowledge, administration practice and adherence among caregivers of chronically ill children in Malaysia
}

Chii-chii Chew ${ }^{1,2^{*}}$ (D, Huan-keat Chan ${ }^{3}$, Chee-tao Chang ${ }^{1}$, Amar-singh HSS $^{1}$ and Mohamed azmi Hassali ${ }^{2}$

\begin{abstract}
Background: Caregivers' knowledge, practice and adherence in medication administration who care for children with chronic illness requiring long-term pharmacological treatments are factors associating with children medication safety at home. This study aimed to determine the medication-related knowledge, administration practice and adherence among caregivers of chronically ill children in Malaysia. This cross-sectional study was conducted at the paediatric outpatient clinic of a tertiary public hospital. Caregivers of chronically ill children, who engaged in medication administration at home for at least 3 months, were conveniently recruited. Their medication-related knowledge and administration practice were evaluated based on a checklist, while their adherence to medication administration was assessed using a validated 5-point scale. The associated factors were also explored.
\end{abstract}

Results: Of the 141 participants, most were mothers (90.8\%) and had a full-time job (55.3\%). Most of them had adequate medication-related knowledge (71.6\%) and an appropriate administration practice (83.0\%). The majority of them (83.0\%) also rated themselves as adherent to medication administration. The participants with a child above 5 years of age $(91.2 \%)$ were found to have a better practice than those with younger children (75.3\%) in medication administration ( $p=0.012$ ). However, those with a child taking two (adjusted OR: 12.53) or three (adjusted OR: 8.29) medications, getting their refills from private health institutions apart from this hospital (adjusted $O R=7.06$ ) and having multiple illnesses (adjusted $O R=21.25$ ) were more likely to be not adherent to medication administration.

Conclusion: Caregivers of chronically ill children in Malaysia generally have sufficient knowledge and an appropriate practice of medication administration at home. Yet, strategies to improve the adherence to medication administration, particularly in those who care for children with complicated health conditions, are warranted.

Keywords: Child, Chronic disease, Caregivers, Parents, Administration and dosage, Medication adherence

\footnotetext{
*Correspondence: chiichii.crcperak@gmail.com

${ }^{1}$ Clinical Research Centre, Hospital Raja Permaisuri Bainun, Ministry of Health, Level 4, Ambulatory Care Centre (ACC), Jalan Raja Ashman Shah, 30450 Ipoh, Perak, Malaysia

${ }^{2}$ Social and Administrative Pharmacy, School of Pharmaceutical Sciences, Universiti Sains Malaysia, 11800 Penang, Malaysia

Full list of author information is available at the end of the article
}

(c) The Author(s). 2021 Open Access This article is licensed under a Creative Commons Attribution 4.0 International License, which permits use, sharing, adaptation, distribution and reproduction in any medium or format, as long as you give appropriate credit to the original author(s) and the source, provide a link to the Creative Commons licence, and indicate if changes were made. The images or other third party material in this article are included in the article's Creative Commons licence, unless indicated otherwise in a credit line to the material. If material is not included in the article's Creative Commons licence and your intended use is not permitted by statutory regulation or exceeds the permitted use, you will need to obtain permission directly from the copyright holder. To view a copy of this licence, visit http://creativecommons.org/licenses/by/4.0/. The Creative Commons Public Domain Dedication waiver (http://creativecommons.org/publicdomain/zero/1.0/) applies to the data made available in this article, unless otherwise stated in a credit line to the data. 


\section{Key messages}

1. $71.6 \%$ of caregiver had adequate medication-related knowledge

2. $83 \%$ of them able to demonstrate appropriate practice in medication administration.

3. $83.0 \%$ of the caregivers rated themselves as adherent to medication administration.

4. Non-adherents were more likely among caregivers deal with a complex regime, refill the medications concurrently from private health institutions and the health facilities where the child had been following up, and child have multiple illnesses.

\section{Introduction}

In general, chronic illnesses in childhood refer to diseases taking place in children below 18 years of age, which last longer than 3 months [1]. The global prevalence of chronic illnesses in childhood has grown by 4 times over the past half century [2]. Consequently, the number of children receiving long-term pharmacological treatment is rising across the world [3]. Unlike adults, young patients are heavily dependent on caregivers in taking medications at home [4-6].

However, insufficient knowledge of medications in caregivers has been resulting in countless adverse drug events in children include overdosing, poisoning or increased risk of growth retardation [5]. Their difficulty in reading drug labels, poor understanding of medication instructions, confusion about different brand names of drugs, unfamiliarity with the devices to be used for medication administration and poor communication with their partners in child care are all known factors contributing to medication errors in children $[5,7,8]$. Thus, education about the medications in caregivers of young children is essential $[6$, 7].

While liquid formulation remains the most common form of dosage form for young children, caregivers, especially those from the developing countries, have difficulties in liquid measurement $[5,7,9]$. Notably, dosing errors in children is three times more prevalent than in adults, and such errors could cause harm in children, particularly those who receive long-term treatment $[4,5$, 10]. Ideally, caregivers should also maintain a record of their medication administration activities and ensure an effective communication with their partners with whom they share their responsibility $[8,9,11]$. Besides helping to achieve the desired outcomes of the treatment, an appropriate medication administration practice is important to avert medication errors and unnecessary hospital visits [5].

When it comes to ensuring the efficacy of pharmacological treatment in children, another key component is the adherence of the caregivers to medication administration.
However, the variations in the degree of parental adherence to medication administration across countries are evident, ranged from 43 to $100 \%$ [12]. In fact, non-adherence to medication administration has been reported to have led to suboptimal treatment outcomes [5], and consequently posed a financial burden to the global healthcare system by resulting in an additional annual expenditure per patient between $\$ 669$ to $\$ 162,699$ US dollars from year 1997 to 2017 [13].

Good parental knowledge in medication were reported associated with those residing in the Western country and having high socioeconomic status [14]. High educational level in caregivers was one of the significant factors associated with good knowledge in the management of childhood asthma [15]. Higher mothers' educational levels and household incomes were also factors positively related to adherence in medication administrations [16]. Consistently, caregivers with low educational levels, being single mothers, having busy schedules and other family responsibilities reported more missed doses [8]. On the other hand, parents' age, education levels, cooking experiences and previous drug administering experiences were not associated with better practice of medication administration, particular in measuring paediatric oral liquid formulation [9]. Another study, however, reported that caregivers' educational levels were not associated with the practice of medication administration, in particular the selection of dosing instrument [17].

As recently highlighted by the Ministry of Health in Malaysia, studies on how medications for children have been handled outside hospital settings remains limited [18]. This study was designed to determine the medication-related knowledge, administration practice, and adherence among caregivers of chronically ill children in Malaysia. What were the level of knowledge, administration practice and level of adherence among the caregivers with regard to their children's medications?

\section{Methods}

This cross-sectional study was conducted between January and April 2019 at the paediatric outpatient clinic of a tertiary public hospital located in northern Malaysia. The diseases treated by the clinic ranges from neurological disorders, developmental delay, asthma, kidney diseases to congenital cardiac defects. It has been visited by 30 to 60 patients each day on an appointment basis.

The main caregivers of children under 12 years of age, who had engaged in the medication administration for at least 3 months, were included in the study [1]. Only the mother was selected if both the parents of a child shared the responsibility for the medication administration, as mothers were shown to have played a more prominent role in child care [19]. On the other hand, caregivers who were not able to communicate in the Malay language or English, or whose children had HIV 
infection, cancer or intellectual impairment, were excluded from the study. The caregivers of these population were not selected mainly because HIV and cancer patients are closely monitored by the healthcare providers and there is a designated pharmacist who will recruit caregivers of HIV patients to attend Medication Therapy Adherence Clinic (MTAC) each time when they come for follow-up. The practices of medication administration among caregivers of children with intellectual impairment are deemed different from that of the general population and hence they were excluded from this study [20].

The participants of the study were recruited using the convenience sampling method. The eligible caregivers were identified from the medical records of their children and were first approached through a telephone call. Written consent was obtained from those who agreed to participate in this study on the day of their following visits to the hospital.

The minimal number of respondents required in this study was 141, calculated by using the formula for prevalence studies with a known population size. It was based on an estimated medication error rate of $33 \%$ and an estimated number of eligible patients fulling the inclusion and exclusion criteria presenting to the clinic in a month $(N=235)$ [8]. The confidence level and precision were fixed at 95 and 5\%, respectively.

A data collection form adapted from Walsh et al. (2008) was used to collect information regarding i) the characteristics of the caregiver (age, relationship with the child, education level, occupation, and marital status) and ii) the characteristics of the child (age, gender and type of chronic illness), iii) the medication-related information documented in the medical records of patients. The knowledge about the medications (names, indications, times of administration, devices used, treatment durations and the dates of the last doses) and the administration practice (maintaining a medication administration record, communication with partners, measurement accuracy, medication preparation method, administration technique and adherence to the prescribed treatment duration and doses) of caregivers were subsequently assessed by the investigator (pharmacist) based on a checklist. In the cases involving liquid medications, the caregivers were also required to demonstrate how they would measure liquid at home by using oral syringes of different sizes $(1 \mathrm{~mL}, 5 \mathrm{~mL}$ and $10 \mathrm{~mL}$ ) or a measuring cup. A metered-dose inhaler and a spacer were also prepared for the caregivers to demonstrate how these devices should be used at home. The device usage and technique were assessed based on standardised medication counselling guidelines published by the Ministry of Health [21]. The 5-point Medication Adherence Report Scale (MAR-5) was used to allow caregivers to rate their adherence level in the medication administration over the past one month. The questionnaire (MARS-5) adapted in both English and Malay languages was validated for its construct validity and reliability (internal consistency and test-retest reliability), and it demonstrated acceptable psychometric properties [22]; in the context of publication right of MARS, the psychometric data are not allowed to be included in this article as per the agreement between the author and the originator. Both the checklist and questionnaire were pretested for understanding prior to data collection. Ethical approval from Medical Research Ethics Committee, Ministry of Health Malaysia was obtained [Research registration number: NMRR-18-228-40,047 (IIR)] and written informed consent from the participants was sought prior to data collection.

The participants were considered to have the right knowledge about the medications if their responses were consistent with the documentation in the medical records of their children and able to provide the details of the medications correctly based on the checklist. Participants were allowed to give either commercial or generic name when they were asked about the medication name. Their practice in medication administration was deemed to be appropriate only if they communicated with their partners or other family members immediately following the medication administration, demonstrated accurate liquid measurement and device handling techniques, and administered the medications at doses and for duration as prescribed.

The adherence level of a caregiver in the medication administration was indicated by a mean score with a possible range from 6 to 30, and a score below 27 indicated non-adherence [23]. The factors associated with the poor knowledge, inappropriate practice and poor adherence, as well as their interactions, were explored using the Pearson's chi-square analysis [24]. The stepwise backward logistic regression analysis was also performed on all the variables with a $p$-value below 0.05 to identify the predictors of poor adherence. The final model was tested for interactions and multicollinearity between the variables, and its fitness was tested using the Hosmer-Lemeshow goodness-of-fit test.

\section{Results}

Of the 141 participants enrolled in this study, most were mothers (90.8\%) and married (95.7\%). They had a mean age of 35.8 (SD: 6.0 ) years. The majority of them had received at least secondary school education $(95.8 \%)$ and had a full-time job (55.3\%). Nearly $60 \%$ of caregivers received helps in the medication administration, mainly from their spouses. On average, they had engaged in the medication administration for 26 (IQR: 26) months. Almost all of them (95.1\%) were able to read the label without help from the others. Most of them (58.9\%) 
Table 1 Characteristic of caregivers and children

\begin{tabular}{ll}
\hline Demographic characteristics & $n(\%) ; n=141$ \\
\hline Caregivers
\end{tabular}

Relationship with child
Mother
Father
Relative

Receiving help from

Another parent

Other family members

None

$128(90.8)$

$12(8.5)$

$1(0.7)$

55 (39.0)

27 (19.1)

$59(41.8)$

Highest educational level

Secondary education

Tertiary education

No formal education/ Primary education

Occupation

Stay-home parents

Professional

Semi-professional

Labourer

Marital status

Married

Single

Requiring help to read medication labels?

Never

Rarely

Always

Never reading

Sources of medications

Only this hospital

Other government-funded hospital/clinic

Private pharmacy/clinic/hospital

Number of medications administered to children

$$
1
$$

2

3

4

\section{Children}

Age, year [mean (SD)]

Gender

Male

Female

83 (58.9)

52 (36.9)

$6(4.2)$

$63(44.7)$

19 (13.5)

45 (31.9)

$14(9.9)$

135 (95.7)

$6(4.3)$

134 (95.1)

$3(2.1)$

$1(0.7)$

$3(2.1)$

119 (84.4)

$7(5.0)$

$10(7.0)$

58 (41.1)

$62(44.0)$

$18(12.8)$

$3(2.1)$

5.45 (3.39)

78 (55.3)

63 (44.7)

Number of chronic illnesses

1

$\geq 2$
Table 1 Characteristic of caregivers and children (Continued)

\begin{tabular}{ll}
\hline Demographic characteristics & $\mathbf{n}(\%) ; \boldsymbol{n}=\mathbf{1 4 1}$ \\
\hline Pharmaceutical Dosage Form $(\boldsymbol{n = 2 4 8})^{\mathrm{a}}$ & \\
Inhalation & $110(44.4)$ \\
Oral liquid & $65(26.2)$ \\
Tablet & $54(21.8)$ \\
Dispersible tablet & $14(5.6)$ \\
Nasal spray & $2(0.8)$ \\
Intravenous injection & $1(0.4)$ \\
Granules & $1(0.4)$ \\
Gargle solution & $1(0.4)$ \\
\hline
\end{tabular}

athere was a total of 248 medication being assessed

dealt with at least two types of medications. Their children were aged 5.45 (SD: 3.39) years on average and mostly had only one type of disease (97.9\%) (Table 1).

Most participants (71.6\%) were found to have sufficient overall knowledge of the medications. They generally had the right knowledge of the indications (82.3\%), the prescribed time and frequency (92.2\%), the prescribed dosage $(92.9 \%)$, and the devices to be used $(100 \%)$ for the medications (Table 2 ).

Most of them (83.0\%) had an appropriate practice in the medication administration. In general, they did communicate with their helpers immediately after the medication administration (87.8\%), performed the liquid measurement correctly (87.8\%), and demonstrated the correct medication preparation $(97.2 \%)$ and administrations (98.6\%) techniques. A small number of them (5.7\%) discontinued the treatment of their children prematurely without seeking advices from physicians (Table 2). An inappropriate medication administration practice was more commonly seen in the participants with a child under 5 years of age $(p=0.012)$ (Table 3$)$.

More than $80 \%$ of the caregivers rated themselves as adherent to the medication administration (Table 2). The type of health institutions from which they obtained their refills besides this hospital $(p=0.020)$ and the number of medications taken by the child $(p<0.001)$ were significantly associated with their adherence level (Table 3 ). The caregivers with children taking a greater number of medications, obtaining refills from private health institutions and with more than one chronic illness had higher odds of being non-adherent to the medication administration (Table 4).

\section{Discussion}

The findings of this study suggest that most caregivers of young children have adequate knowledge about medications and appropriate practice in their administration. In addition, they also have a high adherence level in the medication administration. However, those with children 
Table 2 Medication-related knowledge, administration practice and adherence of caregivers

\begin{tabular}{|c|c|}
\hline Variables & $\begin{array}{l}\text { Correct } \\
\text { /Appropriate } \\
\text { n (\%); } n=141\end{array}$ \\
\hline Knowing the names of medications & $66(46.8)$ \\
\hline Maintaining a record for medication administration & $61(43.3)$ \\
\hline \multicolumn{2}{|l|}{ Overall medication-related knowledge } \\
\hline Adequate & $104(71.6)$ \\
\hline Inadequate & $40(28.4)$ \\
\hline \multicolumn{2}{|l|}{ Individual aspect of medication-related knowledge } \\
\hline Knowing the indications & $116(82.3)$ \\
\hline $\begin{array}{l}\text { Knowing the time and frequency of } \\
\text { administration }\end{array}$ & $130(92.2)$ \\
\hline Knowing the device for administration & $119(100)$ \\
\hline Not involving a device & 22 \\
\hline Knowing the dosage & $131(92.9)$ \\
\hline \multicolumn{2}{|l|}{ Overall practices of medication administration } \\
\hline Appropriate & $117(83.0)$ \\
\hline Inappropriate & $24(17.0)$ \\
\hline Always communicating with partners $(n=82)$ & $72(87.8)$ \\
\hline $\begin{array}{l}\text { Accurate dosage measurement for oral liquid } \\
\text { medication }(n=49)\end{array}$ & $43(87.8)$ \\
\hline Appropriate method of medication preparation & $137(97.2)$ \\
\hline Appropriate technique of administration & $139(98.6)$ \\
\hline Appropriate date of last dose administration & $133(94.3)$ \\
\hline Appropriate dosage & 139 (98.6) \\
\hline \multicolumn{2}{|l|}{ Medication adherence report scale (MARS) } \\
\hline Not adherent $(<27$ Scores $)$ & $24(17.0)$ \\
\hline Adherent & $117(83.0)$ \\
\hline
\end{tabular}

taking a greater number of medications, getting their refills from private health institutions and with more complicated medical conditions were more likely to be less adherent to the medication administration. The findings also help us better understand the issues related to the medication administration in the context of Malaysia [18], and could be used to guide healthcare providers in educating caregiver.

Consistent with the finding of a previous study [8], this study shows that children under 5 years of age are more likely to be victims of an inappropriate medication administration practice. The absence of age-appropriate drug formulations commonly requires caregivers to crush a tablet, reconstitute a powder formulation and accurately measure a liquid formulation [5]. Inappropriate practices are likely to be unavoidable due to the lack of proper techniques and devices, as well poor palatability of the medications $[5,9,25]$. Apart from relying on the pharmaceutical to develop more child-friendly formulations [5], health care providers could educate caregivers how to improve the acceptance of medications in children include informing the caregiver if the medications were compatible with food and masking the poor taste with certain food or drink (e.g. juice) [26] and adopt several strategies well supported by the existing literature, including the use of pictographic instructions and the teach-back method, to avert inappropriate medication administration practices [27-29].

Caregivers were found to be well informed about their children's medications in general. This suggests that health care providers have been providing them with sufficient medication-related information, as highly recommended in the existing guidelines [21,30]. In contrast with caregivers from other developing countries who still tended to use a household spoon for medication administration [7,9], all participants in this study managed to measure the medication correctly by using a proper measuring device. However, unlike other countries [25, 31], caregivers in Malaysia were commonly not familiarized with the generic names of medications [21, 30]. To avoid errors caused by the confusion, it is important to educate them about different names used for a medication, in addition to its indication, dosage, frequency and treatment duration [27].

Having an appropriate practice in the medication administration in most caregivers in this study was suggestive of the sufficiency and accuracy of the medication instructions they received $[21,30]$. Only caregivers who are able to handle the medications correctly at home can shield their children from undesirable adverse events [5]. While dosing errors are common with liquid formulations $[7,8,32]$, it is found that most caregivers in this study were able to perform the measurement according to the instructions.

Non-adherence to the medication administration was more common in the caregivers with children taking a greater number of medications, having multiple medical conditions, and getting their refills from private health institutions apart from this hospital. The need to deal with a complicated treatment regimen has long been a known factor for non-adherence among the caregivers of young children [8]. Users who refilled medications from different health institutions may be facing variations in healthcare services, different adherence counselling structure and varied practice of health care providers in providing adherence educations which may result in decreased adherence [12]. In addition, the absence of an effective information exchange mechanism across different health institutions from which caregivers get their refills could lead to repeated administration of the same medication. While the practice of refilling medications 
Table 3 The associations between characteristics of caregivers and their knowledge of, practice of, and adherence to medication administration

\begin{tabular}{|c|c|c|c|c|c|c|c|c|c|}
\hline \multirow[t]{2}{*}{ Variables } & \multicolumn{3}{|l|}{ Knowledge } & \multicolumn{3}{|l|}{ Practice } & \multicolumn{3}{|l|}{ Adherence } \\
\hline & $\begin{array}{l}\text { Adequate } \\
n=101\end{array}$ & $\begin{array}{l}\text { Inadequate } \\
n=40\end{array}$ & $\begin{array}{l}\text { P- } \\
\text { value }^{a}\end{array}$ & $\begin{array}{l}\text { Appropriate } \\
n=117\end{array}$ & $\begin{array}{l}\text { Inappropriate } \\
n=24\end{array}$ & $\begin{array}{l}\text { P- } \\
\text { value }^{a}\end{array}$ & $\begin{array}{l}\text { Adherence } \\
\mathrm{n}=117\end{array}$ & $\begin{array}{l}\text { Non- } \\
\text { adherent } \\
n=24\end{array}$ & $\begin{array}{l}\text { P- } \\
\text { value }^{a}\end{array}$ \\
\hline Caregivers mean age (SD) & $36.32(5.90)$ & $34.58(6.05)$ & $0.119^{b}$ & $35.93(6.05)$ & $35.29(5.63)$ & $0.634^{b}$ & $35.85(5.96)$ & $\begin{array}{l}35.71 \\
(6.14)\end{array}$ & $0.918^{b}$ \\
\hline Relationship with the child & & & 0.515 & & & 0.744 & & & 0.353 \\
\hline Mother & $93(72.7)$ & $35(27.3)$ & & $105(82.0)$ & $23(18.0)$ & & $104(81.2)$ & $24(18.8)$ & \\
\hline Father & $7(58.3)$ & $5(41.7)$ & & $11(91.7)$ & $1(8.3)$ & & $12(100.0)$ & $0(0.0)$ & \\
\hline Relatives & $1(100.0)$ & $0(0.0)$ & & $1(100.0)$ & $0(0.0)$ & & $1(100.0)$ & $0(0.0)$ & \\
\hline Receiving help from & & & 0.861 & & & 0.296 & & & 0.660 \\
\hline Another parent & $38(69.1)$ & $17(30.9)$ & & $49(89.1)$ & $6(10.9)$ & & $45(81.8)$ & $10(18.2)$ & \\
\hline Other family members & $20(74.1)$ & $7(25.9)$ & & $21(77.8)$ & $6(22.2)$ & & $24(88.9)$ & $3(11.1)$ & \\
\hline None & $43(72.9)$ & $16(27.1)$ & & $47(79.7)$ & $12(20.3)$ & & $48(81.4)$ & $11(18.6)$ & \\
\hline Highest educational level & & & 0.100 & & & 0.139 & & & 0.571 \\
\hline No formal / Primary education & $2(33.3)$ & $4(66.7)$ & & $5(83.3)$ & $1(16.7)$ & & $5(83.3)$ & $1(16.7)$ & \\
\hline Secondary education & $62(74.4)$ & $21(25.3)$ & & $73(88.0)$ & $10(12.0)$ & & $71(85.5)$ & $12(14.5)$ & \\
\hline Tertiary education & $37(71.2)$ & $15(28.8)$ & & $39(75.0)$ & $13(25.0)$ & & $41(78.8)$ & $11(21.2)$ & \\
\hline Occupation & & & 0.067 & & & 0.093 & & & 0.220 \\
\hline Stay-home parents & $50(79.4)$ & $13(20.6)$ & & $56(88.9)$ & $7(11.1)$ & & $55(87.3)$ & $8(12.7)$ & \\
\hline Working caregiver & $51(65.4)$ & 27 (34.6) & & $61(78.2)$ & $17(21.8)$ & & $62(79.5)$ & $16(20.5)$ & \\
\hline Marital status & & & 1.000 & & & 0.270 & & & 0.270 \\
\hline Married & 97 (71.9) & $38(28.1)$ & & $113(83.7)$ & $22(16.3)$ & & $113(83.7)$ & $22(16.3)$ & \\
\hline Single & $4(66.7)$ & $2(33.3)$ & & $4(66.7)$ & $2(33.3)$ & & $4(66.7)$ & $2(33.3)$ & \\
\hline $\begin{array}{l}\text { Duration in medications } \\
\text { administration, months }\end{array}$ & & & 0.829 & & & 0.074 & & & 0.788 \\
\hline$\leq 12$ & $26(68.4)$ & $12(31.6)$ & & $28(73.7)$ & $10(26.3)$ & & 31 (81.6) & $7(18.4)$ & \\
\hline$>12$ & $75(72.8)$ & $28(27.2)$ & & $89(86.4)$ & $14(13.6)$ & & $86(83.5)$ & $17(16.5)$ & \\
\hline $\begin{array}{l}\text { Requiring help to read medication } \\
\text { labels? }\end{array}$ & & & 0.539 & & & 1.000 & & & 1.000 \\
\hline Never & $97(72.4)$ & $37(27.6)$ & & $110(82.1)$ & $24(17.9)$ & & $110(82.1)$ & $24(17.9)$ & \\
\hline Rarely & $2(66.7)$ & $1(33.3)$ & & $3(100.0)$ & $0(0.0)$ & & $3(100.0)$ & $0(0.0)$ & \\
\hline Always & $0(0.0)$ & $1(100.0)$ & & $1(100.0)$ & $0(0.0)$ & & $1(100.0)$ & $0(0.0)$ & \\
\hline Never reading & $2(66.7)$ & $1(33.3)$ & & $3(100.0)$ & $0(0.0)$ & & $3(100.0)$ & $0(0.0)$ & \\
\hline $\begin{array}{l}\text { Where else do you get your } \\
\text { medications? }\end{array}$ & & & 0.928 & & & 0.461 & & & 0.020 \\
\hline Only this hospital & $84(70.6)$ & 35 (29.4) & & $99(83.2)$ & $20(16.8)$ & & $102(85.7)$ & $17(14.3)$ & \\
\hline $\begin{array}{l}\text { Other government funded } \\
\text { hospital/clinic }\end{array}$ & $9(75.0)$ & $3(25.0)$ & & $11(91.7)$ & $1(8.3)$ & & $10(83.3)$ & $2(16.7)$ & \\
\hline Private pharmacy/clinic/ hospital & $8(80.0)$ & $2(20.0)$ & & $7(70.0)$ & $3(30.0)$ & & $5(50.0)$ & $5(50.0)$ & \\
\hline $\begin{array}{l}\text { Number of medications } \\
\text { administered }\end{array}$ & & & 0.863 & & & 0.191 & & & $<0.001$ \\
\hline 1 & $42(72.4)$ & $16(27.6)$ & & $51(87.9)$ & $7(12.1)$ & & $56(96.6)$ & $2(3.4)$ & \\
\hline$\geq 2$ & $59(71.1)$ & $24(28.9)$ & & $66(79.5)$ & $17(20.5)$ & & $61(73.5)$ & $22(26.5)$ & \\
\hline Children age group, years & & & 0.791 & & & 0.012 & & & 0.480 \\
\hline$\leq 5$ & $53(72.6)$ & $20(27.4)$ & & $55(75.3)$ & $18(24.7)$ & & $59(80.8)$ & $14(19.2)$ & \\
\hline$>5$ & $48(70.6)$ & $20(29.4)$ & & $62(91.2)$ & $6(8.8)$ & & $58(85.3)$ & $10(14.7)$ & \\
\hline
\end{tabular}


Table 3 The associations between characteristics of caregivers and their knowledge of, practice of, and adherence to medication administration (Continued)

\begin{tabular}{|c|c|c|c|c|c|c|c|c|c|}
\hline \multirow[t]{2}{*}{ Variables } & \multicolumn{3}{|l|}{ Knowledge } & \multicolumn{3}{|l|}{ Practice } & \multicolumn{3}{|l|}{ Adherence } \\
\hline & $\begin{array}{l}\text { Adequate } \\
n=101\end{array}$ & $\begin{array}{l}\text { Inadequate } \\
n=40\end{array}$ & $\begin{array}{l}\text { P- } \\
\text { value }^{a}\end{array}$ & $\begin{array}{l}\text { Appropriate } \\
n=117\end{array}$ & $\begin{array}{l}\text { Inappropriate } \\
n=24\end{array}$ & $\begin{array}{l}\text { P- } \\
\text { value }^{a}\end{array}$ & $\begin{array}{l}\text { Adherence } \\
n=117\end{array}$ & $\begin{array}{l}\text { Non- } \\
\text { adherent } \\
n=24\end{array}$ & $\begin{array}{l}\text { P- } \\
\text { value }^{a}\end{array}$ \\
\hline Children gender & & & 0.962 & & & 0.744 & & & 0.054 \\
\hline Male & $56(71.8)$ & $22(28.2)$ & & $64(82.1)$ & $14(17.9)$ & & $69(88.5)$ & $9(11.5)$ & \\
\hline Female & $45(71.4)$ & $18(28.6)$ & & $53(84.1)$ & $10(15.9)$ & & $48(76.2)$ & $15(23.8)$ & \\
\hline Number of Chronic diseases & & & 1.000 & & & 1.000 & & & 0.075 \\
\hline One type & $99(71.1)$ & $39(28.3)$ & & $114(82.6)$ & $24(17.4)$ & & $116(84.1)$ & $22(15.9)$ & \\
\hline Two types & $2(66.7)$ & $1(33.3)$ & & $3(100.0)$ & $0(0.0)$ & & $1(33.3)$ & $2(66.7)$ & \\
\hline
\end{tabular}

${ }^{a}$ Analysed with Pearson Chi-square analysis. Fisher's exact test was applied when assumptions for Pearson Chi-square test was not met

${ }^{b}$ analysed with independent T-test

from different institutions to overcome logistic hassles may be beneficial [33], further investigation may be required to explore other reasons of such practice.

As this study was limited to its single-centre design, a similar assessment could be conducted on a larger scale. Convenience sampling of urban population may not reflect reality of all caregivers. Also, the assessment was based on self-reporting of caregivers, and therefore the findings might not reflect their actual practice. It would be more ideal if a direct observation on the medication administration practice at home could be performed in future studies $[6,8]$. Additionally, knowledge of medication side effect among the caregivers could be evaluated

Table 4 Predictors for non-adherence to medication administration, multiple logistic regression analysis

\begin{tabular}{|c|c|c|}
\hline \multirow[t]{2}{*}{ Factors associated with not adherents } & \multicolumn{2}{|l|}{ Not-adherents } \\
\hline & Adj. OR (95\% Cl) & $\begin{array}{l}\mathrm{p}- \\
\text { value }\end{array}$ \\
\hline \multicolumn{3}{|c|}{ Number of medications administered to children } \\
\hline 1 & 1.00 & \\
\hline 2 & $\begin{array}{l}12.53(2.47 \\
63.33)\end{array}$ & $0.002^{*}$ \\
\hline 3 & $8.29(1.21,56.62)$ & $0.031^{*}$ \\
\hline 4 & $9.83(0.01,219.01)$ & 0.149 \\
\hline \multicolumn{3}{|l|}{ Sources of medications } \\
\hline Only this hospital & 1.00 & \\
\hline $\begin{array}{l}\text { Other government funded hospital/ } \\
\text { clinic }\end{array}$ & $1.04(0.19,5.55)$ & 0.968 \\
\hline Private pharmacy/clinic/hospital & $7.06(1.49,33.45)$ & $0.014^{*}$ \\
\hline \multicolumn{3}{|l|}{ Number of Chronic diseases of children } \\
\hline One type of chronic disease & 1.00 & \\
\hline Two types of chronic disease & $\begin{array}{l}21.25(1.16, \\
388.43)\end{array}$ & $0.039^{*}$ \\
\hline
\end{tabular}

Adj. OR: Adjusted odd ratio, Cl: Confidence interval, ${ }^{*} p$-value $<0.05$ in the future in order to better understand if this is one of the reason of medication non-adherence.

\section{Conclusion}

Most of the caregivers in Malaysia had adequate knowledge about the medications received by their children, as well as an appropriate practice and an acceptable adherence level in the medication administration. However, the medication administration practice in caregivers of children below 5 years of age could be further improved. It is also important to ensure the adherence of caregivers of children with complex medical conditions and taking multiple medications. They also need to be advised to get their refills only at the same health institution from which, whenever possible.

\section{Acknowledgments}

Appreciation for sister Khadijah's contribution in this study. Thanks owed to Nurfardilla Ferdaos, a clinical pharmacist, for her helps in this study. Gratitude extend to Dr. Kathleen Walsh for her permission to allow the use of the checklist in this study. The principle investigator wishes to thank Prof Rob Horne for his permission to use the MARS questionnaires for this study. We would like to thank the Director General of Health, Malaysia, for his permission to publish this article.

\section{Authors' contributions}

CC plan, develop, collect data, and wrote the first draft of this research. HK is the second contributor by giving input, critically review, and write this article. $C T$ helped in literature review, critically review and giving input in drafting the manuscript. AS input in the idea of study title, verified data collection form and provide administrative support for this project. MA supervise this project throughout. All authors read, review and approve this manuscript.

\section{Funding}

The author(s) received no financial support for the research, authorship, and/ or publication of this article.

\section{Availability of data and materials}

The datasets generated and/or analysed during the current study are not publicly available due to confidentiality of patients, but are available from the corresponding author on reasonable request. 


\section{Declarations}

\section{Ethics approval and consent to participate}

The ethics approval was obtained from the Medical Research Ethical Committee, Ministry of Health Malaysia. The study was also registered with the National Medical Research Registry under the protocol number NMRR18-228-40047 (IIR). Written informed consent was obtained from all the caregivers prior to the data collection. Participants who were unable to comprehend participant information sheet and give written informed consent were excluded from this study. Participants who declared that they did not receive formal education were recruited only if they could read and comprehend participant information sheet, and give written informed consent prior to participate in this study. This study was conducted in accordance with the Declaration of Helsinki and the Malaysian Guideline for Good Clinical Practice.

\section{Consent for publication}

Not applicable.

\section{Competing interests}

The author(s) declared no potential conflicts of interest with respect to the research, authorship, and/or publication of this article.

\section{Author details}

'Clinical Research Centre, Hospital Raja Permaisuri Bainun, Ministry of Health, Level 4, Ambulatory Care Centre (ACC), Jalan Raja Ashman Shah, 30450 Ipoh, Perak, Malaysia. ${ }^{2}$ Social and Administrative Pharmacy, School of Pharmaceutical Sciences, Universiti Sains Malaysia, 11800 Penang, Malaysia. ${ }^{3}$ Clinical Research Centre, Hospital Sultanah Bahiyah, Ministry of Health, 05460 Alor Setar, Kedah, Malaysia.

Received: 13 March 2021 Accepted: 26 April 2021

Published online: 03 May 2021

\section{References}

1. Mokkink LB, Van Der Lee JH, Grootenhuis MA, Offringa M, Heymans HSA Defining chronic diseases and health conditions in childhood (0-18 years of age): national consensus in the Netherlands. Eur J Pediatr. 2008;167(12): 1441-7. https://doi.org/10.1007/s00431-008-0697-y.

2. Perrin JM, Anderson LE, Van Cleave J. The rise in chronic conditions among infants, children, and youth can be met with continued health system innovations. Health Aff. 2014;33(12):2099-105. https://doi.org/10.1377/hltha ff.2014.0832

3. Cox ER, Halloran DR, Homan SM, Welliver S, Mager DE. Trends in the prevalence of chronic medication use in children: 2002-2005. Pediatrics. 2008;122:2002-5

4. Walsh KE, Mazor KM, Stille CJ, Torres I, Wagner JL, Moretti J, et al. Medication errors in the homes of children with chronic conditions. Arch Dis Child. 2011;96(6):581-6. https://doi.org/10.1136/adc.2010.204479.

5. World Health Organization. Promoting Safety of Medicines for Children. 2007.

6. Walsh KE, Stille CJ, Mazor KM, Gurwitz JH. Using Home Visits to Understand Medication Errors in Children. Adv Patient Saf New Dir Altern Approaches (Vol 4 Technol Medicat Safety). 2008;1-25. http://www.ncbi.nlm.nih.gov/ pubmed/21249963. Accessed 2 Jan 2019.

7. Sil A, Sengupta C, Das A, Sil P, Datta S, Hazra A. A study of knowledge, attitude and practice regarding administration of pediatric dosage forms and allied health literacy of caregivers for children. J Fam Med Prim Care. 2017:6(3):636-42. https://doi.org/10.4103/2249-4863.214433.

8. Parand A, Garfield S, Vincent C, Franklin BD. Carers' medication administration errors in the domiciliary setting: a systematic review. PLoS One. 2016;11(12):1-18. https://doi.org/10.1371/journal.pone.0167204.

9. Mehmood MT, Shah S, Raza S, Athar MS, Ashraf MS, Malik T. Household teaspoon and Oral liquid medication : the present scenario. J Surg Pakistan Int. 2014;19:92-5.

10. Walsh KE, Roblin DW, Weingart SN, Houlahan KE, Degar B, Billett A, et al. Medication errors in the home: a multisite study of children with cancer. Pediatrics. 2013;131(5):e1405-14. https://doi.org/10.1542/peds.2012-2434.

11. Chew CC, HSS AS, Chan HK, Hassali MA. Medication safety at home: a qualitative study on caregivers of chronically ill children in Malaysia. Hosp Pharm. 2019;55(6):405-11. https://doi.org/10.1177/0018578719851719.
12. World Health Organization. World Health Organization. (2003). Adherence to long-term therapies : evidence for action 2003. https://apps.who.int/iris/ha ndle/10665/42682. Accessed 8 Oct 2019.

13. Cutler RL, Fernandez-llimos F, Frommer M, Benrimoj C, Garcia-cardenas V. Economic impact of medication non- adherence by disease groups : a systematic review. BMJ Open. 2018;8(1):e016982. https://doi.org/10.1136/ bmjopen-2017-016982.

14. Cantarero-Arévalo L, Hallas MP, Kaae S. Parental knowledge of antibiotic use in children with respiratory infections: a systematic review. Int J Pharm Pract. 2017;25(1):31-49. https://doi.org/10.1111/ijpp.12337.

15. Kuti B, Omole K. Factors associated with caregivers' knowledge about childhood asthma in llesa, Nigeria. Ann Niger Med. 2016;10(1):30. https://doi. org/10.4103/0331-3131.189806.

16. Ramay BM, Cerón A, Méndez-Alburez LP, Lou-Meda R. Factors associated to acceptable treatment adherence among children with chronic kidney disease in Guatemala. PLoS One. 2017;12:1-12.

17. Yin HS, Dreyer BP, Foltin G, van Schaick L, Mendelsohn AL. Association of low caregiver health literacy with reported use of nonstandardized dosing instruments and lack of knowledge of weight-based dosing. Ambul Pediatr. 2007;7(4):292-8. https://doi.org/10.1016/j.ambp.2007.04.004.

18. Pharmaceutical Services Division, Ministry of Health Malaysia. Pharmaceutical Services Programme; 2018. https://www.pharmacy.gov.my. Accessed 2 Jan 2019.

19. Shorer M, David R, Schoenberg-Taz M, Levavi-Lavi I, Phillip M, Meyerovitch J. Role of parenting style in achieving metabolic control in adolescents with type 1 diabetes. Diabetes Care. 2011;34(8):1735-7. https://doi.org/10.2337/ dc10-1602.

20. Erickson SR, Salgado TM, Tan X. Issues in the medication management process in people who have intellectual and developmental disabilities: a qualitative study of the caregivers' perspective. Intellect Dev Disabil. 2016; 54(6):412-26. https://doi.org/10.1352/1934-9556-54.6.412.

21. Pharmaceutical Services Programme. Garis Panduan Kaunseling Ubat-ubatan Edisi Ke-3. Petaling Jaya; 2019. https://www.pharmacy.gov.my/v2/sites/defa ult/files/document-upload/gp-kaunseling-2019-isbn-final_0.pdf.

22. Horne R, Hankin M. The medication adherence report scale (MARS): a new measurement tool for eliciting patients' reports of non-adherence. London: United Kingdom; 2008. Accessed 5 Feb 2019.

23. Shah NM, Hawwa AF, Millership JS, Collier PS, Ho P, Tan ML, et al. Adherence to antiepileptic medicines in children: a multiple-methods assessment involving dried blood spot sampling. Epilepsia. 2013;54(6):10207. https://doi.org/10.1111/epi.12126.

24. Khan A, Conroy R, Ahmad Z. I hate statistics! Penang, Malaysia: Penang Medical College Malaysia; 2012.

25. Hämeen-Anttila K. Chapter Twelve: Counselling Children - Future Medicine Users. In: Pohjanoksa-Mäntylä M, Yeung SST, Puumalainen I, Airaksinen M, editors. Counselling, Concordance and Communication - Innovative Education for Pharmacists. 2nd editio. Finland: International Pharmaceutical Federation (FIP); 2012. https://www.fip.org/www/streamfile.php?filename= fip/HaMIS/fip_ipsf_pce_2nd_2012.pdf.

26. Hitchings S. Tips to help your child take medication. Oxford; 2018. https:// www.ouh.nhs.uk/patient-guide/leaflets/files/1 1990Pmedicine.pdf. Accessed 20 June 2020

27. Yin HS, Dreyer BP, Moreira HA, Van Schaick L, Rodriguez L, Boettger $S$, et al. Liquid medication dosing errors in children: role of provider counseling strategies. Acad Pediatr. 2014;14(3):262-70. https://doi.org/10.1016/j.acap.2 014.01.003.

28. Chan HK, Hassali MA, Lim CJ, Saleem F, Tan WL. Using pictograms to assist caregivers in liquid medication administration: a systematic review. J Clin Pharm Ther. 2015;40(3):266-72. https://doi.org/10.1111/jcpt.12272.

29. Samuels-Kalow M, Hardy E, Rhodes K, Mollen C. "Like a dialogue": teachback in the emergency department. Patient Educ Couns. 2016;99(4):549-54. https://doi.org/10.1016/j.pec.2015.10.030.

30. Pharmaceutical Services Programme. Paediatric Pharmacy Services Guideline. Petaling Jaya; 2015. https://www.pharmacy.gov.my/v2/sites/defa ult/files/document-upload/clinical-pharmacokinetic-pharmacy-handbookfinal.pdf. Accessed 2 July 2020.

31. Parand A, Faiella G, Franklin BD, Johnston M, Clemente F, Stanton NA, et al. A prospective risk assessment of informal carers' medication administration errors within the domiciliary setting. Ergonomics. 2018;61(1):104-21. https:// doi.org/10.1080/00140139.2017.1330491. 
32. Solanki R, Mondal N, Mahalakshmy T, Bhat V. Medication errors by caregivers at home in neonates discharged from the neonatal intensive care unit. Arch Dis Child. 2017;102(7):651-4. https://doi.org/10.1136/a rchdischild-2016-311877.

33. Travis SS, Bethea LS, Winn P. Medication administration hassles reported by family caregivers of dependent elderly persons. J Gerontol - Ser A Biol Sci Med Sci. 2000;55:412-7.

\section{Publisher's Note}

Springer Nature remains neutral with regard to jurisdictional claims in published maps and institutional affiliations.

Ready to submit your research? Choose BMC and benefit from:

- fast, convenient online submission

- thorough peer review by experienced researchers in your field

- rapid publication on acceptance

- support for research data, including large and complex data types

- gold Open Access which fosters wider collaboration and increased citations

- maximum visibility for your research: over $100 \mathrm{M}$ website views per year

At $\mathrm{BMC}$, research is always in progress. 